\title{
AMATHAMIDE ALKALOIDS IN THE PYCNOGONID, STYLOPALLENE LONGICAUDA, EPIZOIC ON THE CHEMICALLY DEFENDED BRYOZOAN, AMATHIA WILSONI
}

\author{
by J. Sherwood, J. T. Walls and D. A. Ritz \\ (with four tables, two text-figures and one plate)
}

SHERWOOD, J., WALLS, J.T. \& RITZ, D.A., 1998 (31:xii): Amathamide alkaloids in the pycnogonid, Stylopallene longicauda, epizoic on the chemically defended bryozoan, Amathia wilsoni. Pap. Proc. R. Soc. Tasm., 132: 65-70.

https://doi.org/10.26749/rstpp.132.65 ISSN 0080-4703. Department of Entomology, University of Illinois at Urbana-Champaign, 505 S. Goodwin, Urbana, IL 61801, USA (JS); Department of Anatomy and Physiology, University of Tasmania, GPO Box 252-24, Hobart, Tasmania, Australia 7001 (JTW); and Zoology Department, University of Tasmania, GPO Box 252-5, Hobart, Tasmania, Australia 7001 (DAR).

Amathamides comprise a group of brominated alkaloids found in the bryozoan, Amathia wilsoni Kirkpatrick (Gymnolaemata: Ctenostomata). We tested a crude bryozoan extract and purified amathamide $\mathrm{C}$ for their ability to deter feeding by fish, Acanthaluteres spilomelamurus (Quoy and Gaimard, 1824) (leatherjacket), in laboratory assays. Food pellets made with crude extracts ( $1 \%$ dry weight) caused $94 \%$ inhibition of artificial pellet acceptance, while amathamide $\mathrm{C}$ at $0.1 \%$ dry weight caused $86 \%$ inhibition. These results suggest amathamides serve as chemical defences of $A$. wilsoni. Because bryozoans are often colonised by epibionts, we also examined representatives of the epizoic community on $A$. wilsoni, using gas chromatography/mass spectrometry (GCMS) for the presence of amathamides. Of 34 epizoic species tested, only one, the sea spider Stylopallene longicauda Stock which was present in high average densities, contained amathamides in concentrated amounts even when deprived of food for 36 hours. In view of the demonstrated feeding deterrence of amathamides in bryozoans, the relatively high epizoic density of $S$. longicauda and its apparent aposematic colouration suggest that amathamides may also function as chemical defences for $S$. longicauda.

Key Words: pycnogonid, Styllopallene longicauda, bryozoan, secondary metabolites, predator-prey interactions, alkaloids, chemical defence, Amathia wilsoni

\section{INTRODUCTION}

Bryozoans are sedentary, colonial, marine invertebrates. Approximately 4000 extant species and over 15000 recorded fossil species have been described (Ryland 1970). Colony morphology is diverse, and often a single colony overgrows a large area, providing a relatively complex microhabitat in which other invertebrates may take refuge (Buss 1979). Secondary metabolites have been identified from marine bryozoans (Christophersen 1985, Anthoni et al. 1990) and characterised as either alkaloids or bryostatins, a group of 15 macrocyclic lactones possessing antineoplastic activity (Anthoni et al. 1990). Despite the structural diversity of bryozoan secondary metabolites, few studies have examined their ecological roles. Montanari et al. (1996) found the volutamides, also halogenated alkaloid metabolites, from Amathia convoluta Lamouroux, to deter feeding by cooccurring predators. Further, volutamides showed toxicity towards larvae of a sympatrichydroid. Halogenated alkaloids from the congener, $A$. wilsoni, have antibacterial properties (Walls et al. 1993) and might also function in chemical defence.

Bryozoan epifaunal assemblages have also been characterised (Rao \& Ganapati 1980, Stebbing 1971, Gordon 1971), but little attention has been given to the potential presence of chemically mediated associations between bryozoan hosts and their epizoans. Carté \& Faulkner (1986) demonstrated that three nudibranch species sequester secondary metabolites produced by the bryozoan Sessibugula translucens; additionally, one of the species, Tambja eliora, is chemically attracted to the bryozoan and its secondary metabolites, tambjamines, at concentrations less that $10^{-10} \mathrm{M}$. Aside from this study, few investigations have been made into the extent to which bryozoan secondary metabolites are found in marine food webs, and the number of studies documenting specialist invertebrate predators in marine ecosystems remains low relative to terrestrial specialist insects (Hay 1992). This situation seems likely to change, since Cronin et al. (1995) pointed to a growing number of reports of specialised feeding among small sedentary consumers that live on chemically defended hosts.

Amathia wilsoni Kirkpatrick (Gymnolaemata: Ctenostomata) is an arborescent, chitinous (ctenostome) bryozoan that contains amathamides (fig. 1) (Blackman \& Matthews 1985, Blackman \& Green 1987, Blackman \& Fu 1989). These brominated alkaloids display antimicrobial activity (Walls et al. 1993) and are found in A. wilsoni in
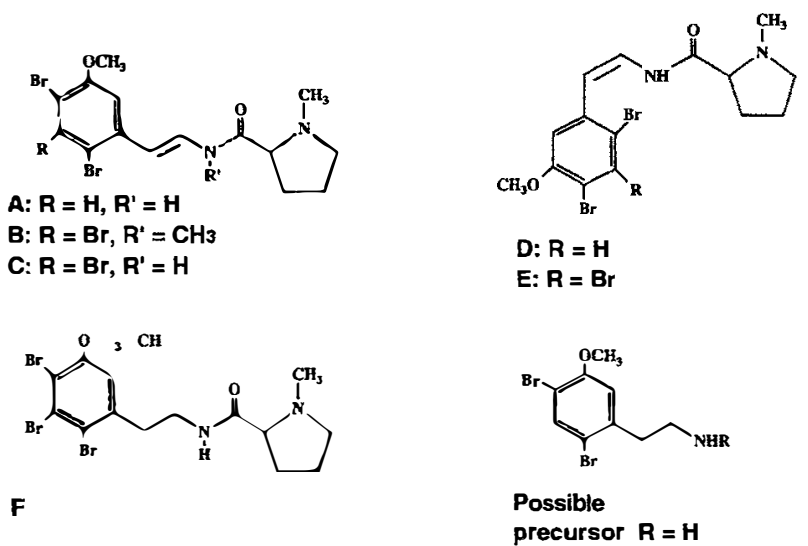

FIG. 1 Structure of amathamide alkaloids A-F and a possible precursor from the bryozoan Amathia wilsoni. 
concentrations up to $9 \%$ dry weight in some regions of the colony (Walls et al. 1991). We tested the ability of amathamides to deter feeding by leatherjackets, Acanthaluteres spilomelamurus, grazing fish sympatric with A. wilsoni. Additionally, to investigate the possibility of chemically mediated feeding specialisation by invertebrate predators, we screened representatives of the epizoic community of $A$. wilsoni for the presence of amathamides.

\section{MATERIALS AND METHODS}

\section{Feeding Deterrence of Amathamides}

A. wilsoni is a common bryozoan in Tasmanian coastal waters (Bock 1982) and occurs abundantly in the coastal rocky reef habitat. Colonies are variable brown to green in colour, erect foliose in structure and range in diameter from 50 to $300 \mathrm{~mm}$. To test the palatability of $A$. wilsoni chemical extracts, either a crude extract of the bryozoan or the purified alkaloid amathamide $\mathrm{C}$, the major secondary metabolite found in A. wilsoni (Walls et al. 1991), was incorporated into food pellets and fed sequentially to test fish, juvenile leatherjackets, Acanthaluteres spilomelamurus (Monacanthidae: Tetraodontiformes). Leatherjackets are common generalist feeders in Tasmanian coastal waters and are widely sympatric with $A$. wilsoni. Further, bryozoans have been isolated from leatherjacket gut contents ( $N$. Barrett, pers. comm.). Test fish were collected throughout 1991 from North West Bay, southern Tasmania, Australia ( $\left.43^{\circ} 3^{\prime} \mathrm{S}, 147^{\circ} 16^{\prime} \mathrm{E}\right)$. A $50 \mathrm{~mm}$ mesh seine was used to trap fish above sea grass beds in the bay. Fish were kept in a large aerated holding tank $(700 \times 350 \times 500 \mathrm{~mm})$ until used in experiments and were fed standard food pellets formulated for Atlantic salmon (Gibsons Ltd, Hobart, Tasmania).

Test diets for $A$. spilomelamurus consisted of $10 \mathrm{ml}$ water, $0.2 \mathrm{~g}$ agar, $0.2 \mathrm{~g}$ fish pellets and $1.0 \mathrm{ml}$ dichloromethane (DCM). Agar, water and crushed fish pellets were boiled and cooled to $60^{\circ} \mathrm{C}$ before addition of DCM. Droplets of liquid mixture were pipetted $(10 \mu \mathrm{l})$ onto petri dishes and then covered and cooled to solidification. Treatment pellets were made identically, except a bryozoan extract or amathamide $\mathrm{C}$ in DCM was added to the agar mixture and the solvent allowed to evaporate before administration.

Crude extracts were made from colonies of $A$. wilsoni collected from waters $5-20 \mathrm{~m}$ deep surrounding Arch Island, southeastern Tasmania $\left(43^{\circ} 17^{\prime} \mathrm{S}, 147^{\circ} 10^{\prime} \mathrm{E}\right)$. Colonies were cleaned of any visible fouling organisms and kept at $-20^{\circ} \mathrm{C}$ before freeze-drying for 48 hours. One hundred grams of wet material was freeze dried, milled and extracted with distilled DCM (Walls et al. 1991) and rotary-evaporated to dryness. Before incorporation into food pellets, a small amount of dried extract was redissolved in $0.9 \mathrm{ml} \mathrm{DCM}$ and analysed by gas chromatography/mass spectrometry. A Hewlett-Packard 5890A GC/MS was used for detection of amathamides, using selected ion monitoring (Walls et al. 1991). The amount of crude extract added to pellets produced an approximate amathamide concentration of about $1 \%$ of pellet dry weight. Previous work estimated total amathamide content in one colony at $1 \%$ dry weight and amathamide $\mathrm{C}$ content at $0.5 \%$ dry weight, i.e. approximately half of total (Walls et al. 1991).

The most abundant amathamide in $A$. wilsoni, amathamide C (Walls et al., 1991), was purified by following the procedures of Blackman \& Green (1987) and tested for feeding deterrence. To ensure pure amathamide $\mathrm{C}$ was obtained, GC/MS was performed on the extract before incorporation into treatment pellets. Pellets were made as above with crude extracts, except final concentrations of amathamide $\mathrm{C}$ were approximately $0.1 \%$ of food pellet dry weight. We did not have enough purified amathamide $C$ to mimic the natural concentration in $A$. wilsoni. Separate feeding assays testing the effects of added DCM on pellet acceptability showed that the solvent did not change feeding behaviour (Walls 1993).

Two separate feeding trials were performed in a manner similar to those described by Gerhart et al. (1991). In each trial, 30 individual test fish were starved for 24 hours before being offered, sequentially, a control pellet, treatment pellet, treatment pellet, and finally another control pellet. Rates of pellet acceptance for the two treatments were compared statistically using $\mathrm{G}$-tests for independence with Yates' correction (Sokal \& Rohlf 1981). Percentage inhibition of feeding attributed to treatments relative to controls was calculated (from combined data) as the difference between control and treatment acceptance rates, divided by the control rate (Gerhart et al., 1991). Also, first and last control pellet acceptance was compared statistically as above. Thus, the use of single pellets allowed for detection of facilitation or inhibition of feeding during the experiment. Thirty sets of four pellets were offered to each fish in each trial, and results were scored as either one for completely eaten, one-half for a mouthed and then rejected pellet, and zero for an untouched pellet. Scores for both control and treatment pellets were pooled and percentages of number eaten were calculated.

\section{Alkaloid Screening and Epizoic Community Density}

Ecologically significant interactions of an epibiont with its host might be a function of abundance, so densities of pycnogonids on collected bryozoans were estimated. Twelve colonies of $A$. wilsoni were collected during July and August 1992, from waters 9-15 m deep at Deep Glen Bay, Forestier Peninsula, southeastern Tasmania, Australia (42058' $\mathrm{S}$ and $147^{\circ} 58^{\prime} \mathrm{E}$ ). Ten colonies were preserved in $7 \%$ formalin and transferred to $70 \%$ ethanol for collection of epizoans. For comparison, two colonies of each of three species of catenicellid cheilostome bryozoan were collected and preserved to determine densities of co-occurring pycnogonid species. These calcified bryozoans, Orthoscuticella ventricosa Busk, Costaticella hastata Busk and Paracribricellaria cribraria Busk, are also arborescent, contain brominated alkaloids and are sympatric with $A$. wilsoni. Plastic bags were placed over individual colonies, which were then pulled from the substrate at the holdfast. Pycnogonid densities were expressed in terms of bryozoan colony volumes which were measured by water displacement. Pycnogonids were removed by shaking individual bryozoan colonies in a bucket of water, which was then filtered, using a $500 \mu \mathrm{m}$ mesh. Pycnogonids were then counted and identified. Total abundance was divided by colony volume and multiplied by 100 to calculate a size-specific pycnogonid density for each bryozoan colony as number of individuals per $100 \mathrm{ml}$ bryozoan colony.

From two remaining colonies, pycnogonids were collected, identified and maintained in aerated sea water aquaria for 36 hours to allow passage of gut contents. After that time, individuals were freeze-dried for 48 hours and 
then extracted once for 24 hours with $3 \mathrm{ml}$ DCM. Additionally, to compare pycnogonid extracts with bryozoan host extracts, frond tip sections of $A$. wilsoni were freezedried and extracted. Resultant crude extracts were then screened for the presence of amathamides by GC/MS. Retention times and mass spectrometric fragmentation signatures of extracts were analysed and compared between bryozoan host and epizoan for amathamide presence.

\section{RESULTS}

\section{Predator Deterrence of Bryozoan Alkaloids}

Both the crude bryozoan extract and amathamide C significantly lowered pellet acceptance rates relative to control rates (table 1) (amathamide C: treatment pellet 1, Yates' corr. $\mathrm{G}=30.9, \mathrm{df}=1, \mathrm{P}<0.005$; treatment pellet 2, Yates' corr. $\mathrm{G}=40.0, \mathrm{df}=1, \mathrm{P}<0.005$; crude extract: treatment pellet 1 , Yates' corr. $G=47.4, d f=1, P<0.005$; treatment pellet 2, Yates' corr. $\mathrm{G}=56.6, \mathrm{df}=1, \mathrm{P}<0.005)$. Control pellet acceptance rates did not differ significantly between the beginning and the end of either amathamide $C$ or crude extract experiments (Yates' corr. $\mathrm{G}=0.0, \mathrm{df}=1, \mathrm{P}>0.10$ ). Results of both experiments were combined to calculate the relative potency of $0.1 \%$ amathamide $\mathrm{C}$ and $1.0 \%$ crude extract treatments. Feeding inhibition was slightly higher for the crude extract (94\% inhibition of pellet consumption relative to controls), than for $0.1 \%$ amathamide $\mathrm{C}$ alone ( $87.5 \%$ inhibition) (table 1 ). Since these experiments were conducted at different times, the significance of this difference could not be tested. Rates of acceptance of first and last control pellets were not significantly different (table 2), nor were those of first and second test pellets, though fewer of the second were taken than the first. Thus, no significant facilitation or inhibition of feeding by the leatherjackets was detected during the experiments; this suggests a lack of a learned-aversion response in this species.

\section{Alkaloid Screenings and Epizoic Community Density}

Thirty-four epizoic species were screened for amathamides (table 3). Of these, bryozoan predators might have been expected only among the gastropods, polychaetes, pycnogonids and possibly decapods. In fact, only one species, the pycnogonid Stylopallene longicauda, contained amathamides. Gas chromatograms of pycnogonid extracts showed peaks with retention times characteristic of amathamides (fig. 2) (Walls et al. 1991, Blackman \& Matthews 1985, Blackman $\&$ Green 1987). Mass spectrometric fragmentation patterns verified, by the presence of a predominant 84 amu signal corresponding to the $\mathrm{N}$-methylpyrrolidine ion, four amathamide peaks in the gas chromatogram of S. longicauda.

From the ten bryozoan colonies, the average density of S. longicauda is an order of magnitude greater than its density on the catenicellid bryozoans and any other pycnogonid found on A. wilsoni (table 4). High variance in density estimated was due to the presence of three colonies possessing upwards of 160 pycnogonid juveniles.Several attempts to observe feeding by $S$. longicauda in situ on a bryozoan colony were unsuccessful.
TABLE 1

Relative palatability of pellets containing crude extract of Amathia wilsoni and amathamide $\mathrm{C}$ to leatherjackets (Acanthaluteres spilomelanurus)

\begin{tabular}{lccc}
\hline Treatment & $\begin{array}{c}\text { No. } \\
\text { pellets }\end{array}$ & $\begin{array}{c}\text { Pellets } \\
\text { eaten (\%) }\end{array}$ & $\begin{array}{c}\text { Feeding } \\
\text { inhibition (\%) }\end{array}$ \\
\hline Crude Extract & 60 & 5.8 & 94 \\
Control & 60 & 94 & 6 \\
Amathamide C & 60 & 12.5 & 87.5 \\
Control & 60 & 90 & 10 \\
\hline
\end{tabular}

* Percentage of first and second pellets eaten for both treatments was significantly different to percentage of control pellets eaten (G-test, $\mathrm{p}<0.005)$. See text for other statistical details.

TABLE 2

Rates of acceptance of first and last control pellets by Acanthaluteres spilomelanurus

\begin{tabular}{lccc}
\hline Treatment & $\begin{array}{c}\text { Eaten* } \\
(\mathrm{N})\end{array}$ & $\begin{array}{c}\text { Not eaten } \\
(\mathrm{N})\end{array}$ & $\begin{array}{c}\text { Yates' } \\
\text { corrected G }\end{array}$ \\
\hline Crude Extract & & & \\
$\quad$ First Control Pellet & 28 & 2 & 0.0 \\
Last Control Pellet & 28.5 & 1.5 & \\
& & & \\
Amathamide C & & & 0.0 \\
First Control Pellet & 26.5 & 3.5 & \\
Last Control Pellet & 27.5 & 2.5 & \\
\hline
\end{tabular}

* Pellets that were mouthed and rejected were scored as 0.5 .

TABLE 3

Epizoic organisms screened for amathamides

\begin{tabular}{lll}
\hline Taxon* & No. & \\
\hline Amphipoda & 7 & nd \\
Ascidiaceae & 2 & nd \\
Bivalvia & 2 & nd \\
Bryozoa & 2 & Emma rotunda, Membranipora perfragilis \\
Decapoda & 2 & nd \\
Echinoidea & 1 & nd \\
Gastropoda & 5 & nd \\
Hydrozoa & 1 & nd \\
Isopoda & 1 & nd \\
Ophiuroidea & 1 & nd \\
Polychaeta & 4 & Trypanosyllis zebra, Syllidae sp., 2 nd \\
Porifera & 1 & nd \\
Pycnogonida & 5 & Achelia assimilis, Stylopallene longicauda, \\
& & Pseudopallene ambigua, P. pachychiera, \\
& & P. sp.
\end{tabular}

\footnotetext{
* Epizoic taxa.

+ Number of species per taxon.

¥ Species names (when determined) of organisms extracted and analysed for presence of amathamides using GC/MS; nd = not determined.
} 


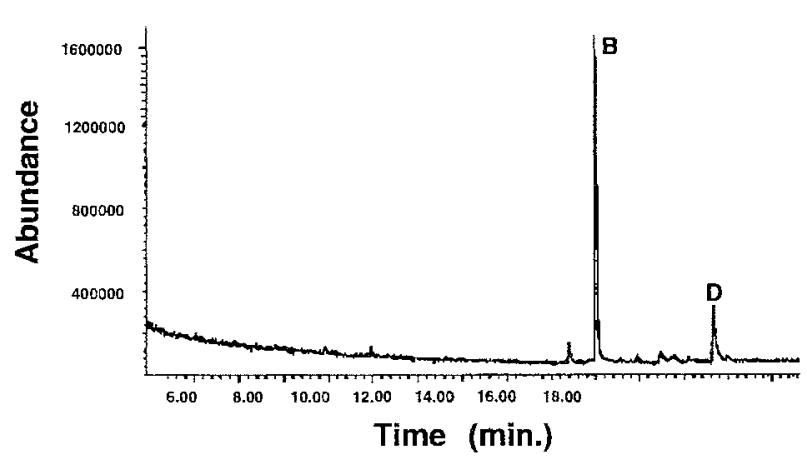

FIG. 2 - Selected Ion Monitoring gas chromatogram (SIM) trace of DCM extract of Srylopallene longicauda. Peaks represent amathamides verified by mass spectrometry. See Walls et al. (1991) for procedural details. B - amathamide B; $D$ - amathamide $D$.

TABLE 4

Average densities of ten species of pycnogonid epizoic on Amathia wilsoni and three catenicellid bryozoans

\begin{tabular}{lcc}
\hline $\begin{array}{l}\text { Pycnogonid } \\
\text { Amathia wilsoni } \\
\mathrm{n}=10\end{array}$ & $\begin{array}{c}\text { Catenicellids } \\
\mathrm{n}=6\end{array}$ \\
\hline Achelia assimilis & & \\
Achelia transfugoides & $0.9 \pm 2.2$ & $0.2 \pm 0.5$ \\
Ammothea ovatoides & $0.2 \pm 0.6$ & $0.4 \pm 0.7$ \\
Ammotheidae sp. & $0.5 \pm 1.2$ & 0 \\
Pseudopallene pachychiera $^{*}$ & $0.1 \pm 0.4$ & 0 \\
P. ambigua* & $0.1 \pm 0.3$ & $0.2 \pm 0.4$ \\
P. sp.1 & $0.7 \pm 2.3$ & $0.8 \pm 1.2$ \\
P. sp.2 & $0.2 \pm 0.4$ & $0.2 \pm 0.5$ \\
Pycnogonum aurilineatum & $0.2 \pm 0.5$ & 0 \\
Stylopallene longicauda* & $0.1 \pm 0.4$ & 0 \\
\hline
\end{tabular}

* Species extracted and screened for amathamide alkaloids. $\dagger$ Densities reported as number of individuals per $100 \mathrm{ml}$ bryozoan colony.

\section{DISCUSSION}

Amathamides produced by $A$. wilsoni deter feeding by A. spilomelamurus and may serve as chemical defences against generalist predators. Levels of inhibition associated with amathamide C-treated pellets were slightly lower than levels of inhibition associated with crude extract-treated pellets. This could be because absolute amounts of secondary metabolites in the pellets were different. But if it was an indication either that other amathamides deter feeding more effectively than amathamide $\mathrm{C}$, or that mixtures of the amathamide array might be working more effectively than amathamide $\mathrm{C}$ alone, it would repay further study. For example, synergistic interactions have been documented for chemically defended terrestrial plants (Berenbaum \& Neal 1985, Berenbaum 1985) and for marine invertebrates (Hay et al. 1994). Variation in physiological effects among compounds with similar structures is documented (Hay $\&$ Fenical 1988). A. wilsoni possesses a range of structurally similar alkaloids (fig. 1) that may be more effective against a greater range of potential predators than individual compounds.
Hay et al. (1987) found seaweed secondary metabolites to be deterrent to predatory fish and sea urchins, but found no effect on feeding by an amphipod. It would be interesting to test the effectiveness of amathamides against generalist invertebrate predators of bryozoans. As food preferences often change with maturity, assumptions about the similarities in diet between adult and juvenile fish must also be made with care. Our feeding trials with $A$. spilomelamurus, however, suggest that amathamides play a part in chemically defending $A$. wilsoni from predation.

Distribution patterns of amathamides support present feeding assay results which suggest amathamides act as chemical defences for the bryozoan (Walls et al. 1991). In this study, Walls et al. showed amathamides to vary in concentration and distribution within single colonies; outermost, exposed tips had an alkaloid content of nearly $9 \%$ dry weight, while basal parts were devoid of alkaloids. Samples taken midway between tips and base yielded intermediate concentrations of about $1 \% \mathrm{dry}$ weight. Assuming some metabolic cost of amathamide chemical defence production, and that the exposed and actively asexually reproducing bryozoan tips are more valuable to the colony than other regions, amathamide allocation in $A$. wilsoni is consistent with current optimal defence theory. This theory predicts that plant parts most important and susceptible to predation will be most defended (Rhodes 1979). Such regions of a plant, therefore, should contain higher concentrations of chemical defences than other relatively unexposed and unimportant regions (Zangerl \& Bazzaz 1992).

Many associations between pycnogonids and marine invertebrates have been documented (scyphozoans - Child \& Harbison 1986, Arnaud \& Bamber 1987; hydroids Russell \& Hedgepeth 1990, Staples 1987; bivalves Ohshima 1933, Ogawa \& Matsuzaku 1985, Benson \& Chivers 1960; opisthobranchs - Piel 1991, Arnaud 1978; starfish - Stock 1981; ophiuroids - Sloan 1979; bryozoans - Wyer \& King 1973), and pycnogonids are among the few documented specialised predators of bryozoans (Ryland 1976). The present study provides another example of a sea spider-host interaction. S. longicauda has only ever been reported from Westernport Bay, Victoria, where it is very common on Amathia biseriata. Other sea spiders counted, some even in the same family as $S$. longicauda, do not occur in such high densities on $A$. wilsoni or any of the three catenicellids. The relatively low density of $S$. longicauda on the sympatric catenicellid bryozoans, one of which also produces halogenated alkaloids (Blackman et al. 1987), indicates $S$. longicauda preferentially resides amongst the fronds of $A$. wilsoni.

The presence of amathamides in starved specimens of $S$. longicauda may indicate these amathamides are sequestered in tissues of the sea spider for defensive purposes. That the density of $S$. longicauda on $A$. wilsoni was an order of magnitude greater than that of any other pycnogonid identified in this study (table 4), further supports the notion that $S$. longicauda may be a specialist predator on $A$. wilsoni; indeed the density of $S$. longicauda on $A$. wilsoni is the highest reported to date (Anonymous 1980, Arnaud \& Bamber 1987). Finally, S. longicauda appears to be aposematically coloured; individuals are circularly banded with strongly contrasting black and white regions, a pattern that could clearly present itself over all wavelengths of visible light, and hence depths (pl. 1). This would be consistent with Lindquist \& Hay (1996), who described a 


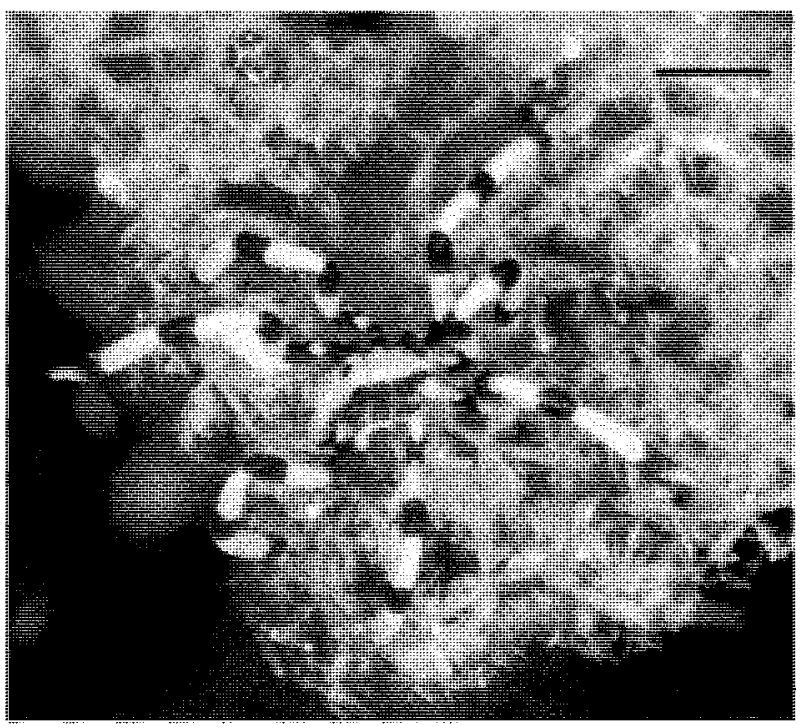

PLATE 1

Stylopallene longicauda on Amathia wilsoni. Note black and white banding as possible aposematic coloration. Bar is $0.5 \mathrm{~cm}$.

positive correlation between frequency of bright colouration of larvae and their unpalatability to fish. Reports of pycnogonids as prey are inconsistent. Although they may be a relatively poor food item (King 1973, Arnaud \& Bamber 1987, Anonymous 1980), they have recently been found in gut contents of blenniid fishes (Krapp \& Nieder 1993). Thus, there is some evidence of predation on sea spiders, which could provide a selective force for defence, gained through a particular feeding specialisation.

There are few reported cases of chemical defences in pycnogonids. Tomaschko (1994) demonstrated that the sea spider Pycnogonum littorale possesses moulting hormones, ecdysteroids, which deter feeding by the common shore crab, Carcinus maenas. Along with this recent finding, our study documents possible chemical defences in these primitive marine chelicerates. Moreover, our findings suggest $S$. longicauda may be preferentially associating with A. wilsoni in order to gain these chemical defences. It remains to be seen if the many documented associations between sea spiders and other marine invertebrates are chemically mediated.

\section{ACKNOWLEGEMENTS}

We would like to thank the Carl and Sarah Morgan Foundation and the William R. Murchie Fund for partially funding the research. We also thank Noel Davies for his GC/MS expertise. R. Mawbey and R. Holmes of the University of Tasmania assisted in fieldwork. Pycnogonids were expeditiously identified by D. Staples of the Museum of Natural History, Victoria, Australia.

\section{REFERENCES}

Anonymous, 1980: Pycnogonids in N.E. Atlantic food webs: the uneaten sea spider? Natl. Environ. Res. Counc. News J. 2: $9-10$.

Anthoni, U., Nielson, P.H., Pereira, M. \& Christopherson, C., 1990: Bryozoan secondary metabolites: a chemotaxonomical challenge. Comp. Biochem. Phys. 96B: 431437.

ARnaud, F., 1978: A new species of Ascorhynchus (Pycnogonida) found parasitic in an opisthobranchiate mollusc. Zool. J. Linn. Soc. Lond. 63: 99-104.

Arnaud, F. \& Bamber, R.N., 1987: Biology of Pycnogonida. Adv. Mar. Biol. 24: 1-96.

Benson, P.H. \& Chivers, D.C., 1960: A pycnogonid infestation of Mytilus californicus. Veliger 3:16-18.

Berenbaum, M.R., 1985: Brementown revisited: Interactions among allelochemicals in plants. In Cooper-Driver G.A., Swain, T. \& Conn, E.E. (Eds): CHEMICALLY MEDIATED INTERACTIONS BETWEEN PLANTS AND OTHER ORGANISMS. Recent Adv. Phytochem. 19. Plenum Press, New York: 139-169.

Berenbaum, M.R. \& Neal, J.J., 1985: Synergism between myristicin and xanthotoxin, a naturally cooccurring plant toxicant. J. Chem. Ecol.11:1349-1358.

BlACKMAN, A.J. \& FU, S.L., 1989: A B-phenylethylamine-derived possible biosynthetic precursor to the amathamide alkaloids from the bryozoan Amathia wilsoni. J. Nat. Prod. 52: 436-438.

Blackman, A.J. \& Green, R.D., 1987: Further amathamide alkaloids from the bryozoan Amathia wilsoni. Aust. J. Chem. 40: 1655-1662.

BlaCKMAN, A.J. \& MATTHEWS, D.J., 1985: Amathamide alkaloids from the marine bryozoan Amathia wilsoni Kirkpatrick. Heterocycles 23: 2829-2833.

Blackman, A.J., Matthews, D.J. and Green, R.D., 1987: Bcarboline al kaloids from the marine bryozoan Costaticella hastata. J. Nat. Prod. 50: 494-496.

Bock, P.E., 1982: Bryozoans (Phylum Bryozoa). In Shepard, S.A. \& Thomas, I.M. (Eds): MARINE INVERTEBRATES OF SOUTHERN AUSTRALIA. PART I. South Australian Government: 319-394.

Buss, L.W., 1979: Habitat selection, directional growth and spatial refuges: Why colonial animals have more hiding places. In Rosen, B. \& Larwood, G. (Eds): BIOLOGY AND SYSTEMATICS OF COLONIAL ORGANISMS. Academic Press, London: 459-498

CARTÉ, B. \& FAULKNER, D.J., 1986: Role of secondary metabolites in feeding associations between a predatory nudibranch, two grazing nudibranchs and a bryozoan. J. Chem. Ecol. 12: 795-804.

ChILD, C.A. \& HARBISON, G.R.A., 1986: A parasitic association between a pycnogonid and a scyphomedusa in midwater. J. Mar. Biol. Assoc. UK 66: 113-117.

Christophersen, C., 1985: Secondary metabolites from marine bryozoans: A review. Acta Chem. Scand. B 39: 517-529.

Cronin, G., Hay, M.E., Fenical, W. \& Lindquist, N., 1995: Distribution, density and sequestration of host chemical defenses by the specialist nudibranch Tritonia hamnerorum found at high densities on the seafan Gorgonia ventalina. Mar. Ecol. Prog. Ser. 119: 177-189.

Faulkner, D.J. \& Ghislen, M.T., 1983: Chemical defense and the evolutionary ecology of dorid nudibranchs and some other opisthobranch gastropods. Mar. Ecol. Prog. Ser. 13: 295-301.

Gerhart, D.J., Bondura, M.E. \& Commito, J.A ., 1991: Inhibition of sunfish feeding by defensive steroids from aquatic beetles: structure-activity relationships. J. Chem. Ecol. 14: 1905-1917. 
Gordon, D.P., 1971: Biological relationships of an intertidal bryozoan population. J. Nat. Hist. 6: 503-514

HAY, M.E., 1992: The influence of algal secondary metabolites in the evolution of marine specialist grazers. In Paul, $\mathrm{V}$. (Ed.): ECOLOGICAL ROLES OF MARINE NATURAL PRODUCTS. Comstock, London.

Hay, M.E. \& Fenical, W., 1988: Marine plant herbivore interactions: the ecology of chemical defense. Ann. Rev. Ecol. Syst. 19: 111-145.

Hay, M.E., Duffy J.E., Pfister, C.A. \& Fenical, W., 1987: Chemical defense against different marine herbivores: are amphipods insect equivalents? Ecology 68:1567-1580.

Hay, M.E., Kappel, Q.E. \& FeniCal, W., 1994: Synergisms in plant defenses against herbivores - interactions of chemistry, calcification, and plant quality. Ecology 75: $1714-1726$.

KING, P.E., 1973: PYCNOGONIDS. Hutchinson, London.

Krapp, F. \& Nieder, J., 1993: Pycnogonids as prey of blenniid fishes. Cah. Biol. Mar. 34: 38.

Lindquist, N. \& HAY, M.E., 1996: Palatability and chemical defense of marine invertebrate larvae. Ecol. Monogr. 66: $431-450$.

Montanari, A.M., Fenical, W., Lindquist, N., Lee, A.Y. \& CLARDY, J., 1996: Volutamides A-E, halogenated alkaloids with antifeedant properties from the Atlantic bryozoan Amathia convoluta. Tetrahedron 52: 5371-5380.

Ogawa, K. \& Matsuzaku, K., 1985: Discovery of bivalveinfesting Pycnogonida, Nymphonella tapetis, in a new host, Hiatella orientalis. Zool. Sci. 2: 583-589.

OHshima, H., 1933: The adult of the bivalve-infesting pycnogonid, Nymphonella tapetis Ohshima. Annot. Zool. Jpn 14: 53-60.

PIEL, W.H., 1991: Pycnogonid predation on nudibranchs and ceratal autotomy. Veliger 34: 366-367.

RaO, K.S. \& Ganapati, P.N., 1980: Epizoic fauna of Thalamoporella gothica var. indica and Pherusella tubulosa (Bryozoa). Bull. Mar. Sci. 30: 34-44.

RHodes, D.F., 1979: Evolution of plant chemical defences against herbivory. In Rosenthal, G.A. \& Janzen, D.H. (Eds): HERBIVORES: THEIR INTERACTION WITH SECONDARY PLANT METABOLITES. Academic Press, New York: 3-54

Russel, D.J. \& HedgePeth, J.W., 1990: Host utilization during ontogeny by two pycnogonid species, Tanystylum duospinum and Ammothea hilgendorfi parasitic on the hydroid Eucopella everta (Coelenterata: Campanulariidae). Bijdr. Dierkd. 60: 3-4.
RYLAND, J.S., 1970: BRYOZOANS. Hutchinson, London.

RyLAND, J.S. 1976: Pycnogonid predators. Adv. Mar. Biol. 14: 417-421.

SLOAN, A . 1979: A pycnogonid-ophiuroid association. Mar. Biol. 52: 171-176.

SOKAL, R.R. \& ROHLF, F.J., 1981: BIOMETRY, THE PRINCIPLES AND PRACTICE OF STATISTICS IN BIOLOGICAL RESEARCH. 2nd edn. Freeman, San Francisco.

STAPLES, D.A., 1987: Association between pycnogonids and hydroids. In Bouillon, J. et al. (Eds): MODERN TRENDS IN THE SYSTEMATICS, ECOLOGY, AND EVOLUTION OF HYDROIDS AND HYDROMEDUSAE. Clarendon Press, Oxford.

STEBBing, A.R.D., 1971: The epizoic fauna of Flustra foliaced (Bryozoa). J. Mar. Biol. Assoc. UK 51: 283-300.

STOCK, J.H., 1981: Pycnogonides. 1. Pycnosomia asterophila, a sea spider associated with the starfish Calliaster from the Phillipines. Resultats des Campagnes Musorstom I. Phillipines (18-28 Mars, 1976). Mem. Mus. Paris 91: 309-312.

TOMASCHKo, K.H., 1994: Ecdysteroids from Pycnogonum littorale (Arthropoda, Pantopoda) act as chemical defence against Carcinus maenas (Crustacea, Decapoda). J. Chem. Ecol. 20: $1445-1455$.

WaLLS, J.T. 1993: Chemical ecology of four bryozoan species from Tasmanian coastal waters. Unpubl. PhD thesis, Univ. Tasm.

Walls, J.T., BlackMan, A.J. \& Ritz, D.A., 1991: Distribution of amathamide alkaloids within single colonies of the bryozoan Amathia wilsoni. J. Chem. Ecol. 17: 18711881.

Walls, J.T., Ritz, D.A. \& Blackman, A.J., 1993: Fouling, surface bacteria and antibacterial agents of four bryozoan species found in Tasmania, Australia. J. Exp. Mar, Biol. Ecol. 169: 1-13.

WyER, D.W. \& KInG, P.E., 1973: Relationships between some British littoral and sublittoral bryozoans and pycnogonids. In Larwood, G.P. (Ed.): LIVING AND FOSSIL BRYOZOA: RECENT ADVANCES IN RESEARCH. Academic Press, New York: 199-208

ZANGerL, A.R. \& BAZZAZ, F.A., 1992: Theory and pattern in plant defence allocation. In Fritz, R.S. \& Simms, E.L. (Eds): PLANT RESISTANCE TO HERBIVORES AND PATHOGENS: ECOLOGY, EVOLUTION AND GENETICS. University of Chicago Press, Chicago.

(accepted 28 September 1998) 